\title{
MICROSTRUCTURAL STUDY OF FAILURE PHENOMENA IN WC 94\%-CO 6\% HARD METAL ALLOY TIPS OF RADIAL PICKS
}

\author{
Sakuntala Nahak ${ }^{1}$, Somnath Chattopadhyaya ${ }^{2}$, Saurabh Dewangan ${ }^{3}$, \\ Sergej Hloch ${ }^{4}$, Grzegorz Krolczyk ${ }^{5}$, Stanislaw Legutko ${ }^{6}$
}

1 Department of Mechanical Engineering, Jaypee University of Engineering and Technology, Guna 473226, India

2 Department of Mechanical Engineering, Indian Institute of Technology (ISM), Dhanbad 826004, India

${ }^{3}$ Department of Mechanical Engineering, National Institute of Science and Technology, Berhampur 761008, India, e-mail: saurabh22490@gmail.com

${ }^{4}$ Faculty of Manufacturing Technologies, Technical University of Kosice with a Seat in Presov, 080 01, Slovakia

5 Opole University of Technology, 76 Proszkowska St., 45-758 Opole, Poland

${ }^{6}$ Faculty of Mechanical Engineering and Management, Poznan University of Technology, ul. Piotrowo 3, 60965 Poznan, Poland

Received: 2016.12.15

Accepted: 2017.02.01

Published: 2017.03.01

\begin{abstract}
An excellent combination of hardness, strength, stiffness and high melting point has proved the WC-Co as an ideal material for tools that are used for metal cutting, coal mining, oil drilling, etc. The ongoing research in WC-Co is focussed on enhancing its wear resistant properties as much as possible. For the purpose, many attempts have been made to study the tribological behaviour of WC-Co for a long time. Researchers have used various grades of WC-Co in different working environments and accordingly they have characterized the wear phenomena involved there within. In this direction of research, the present paper makes an attempt to understand various wear behaviours in WC 94\%-Co 6\% hard metal alloy. WC-Co was used as a tip of the coal cutting tool named radial pick. Two radial picks have been taken for critical analysis through field emission scanning electron microscopy (FESEM) attached with energy dispersive Xray spectroscopy (EDS). In this work, the failure behaviours in the tools have been divided into five categories: (1) Abrasion on individual grain; (2) Corrosion in carbide grains; (3) Fragmentation and removal of WC grains; (4) Pores in WC grains; and (5) Coal and rock embedding. The most possible reasons behind each failure phenomenon have been explained comprehensively with the help of high-resolution microscopic images. However, it is usually observed that, initially, the tool gets minor cracks due to sudden impact. These cracks provide a path to the rock and coal particles to get entrenched inside the microstructure of cemented carbide. Finally, the intermixed external elements degrade the binder content (i.e. cobalt) and the tool becomes useless.
\end{abstract}

Keywords: Radial picks, WC-Co tip, FESEM, EDS, failure behaviour.

\section{INTRODUCTION}

WC-Co cemented carbide has its wide application in the field of coal mining, metal cutting, and oil drilling because of its excellent hardness, strength and wear resistant property. It is mainly used as a tip part of the tools. However, the use- ful properties of the WC-Co may lessen with various physical and chemical properties of the work material, high temperature generation and chemical involvement during operation, and different operating conditions. Coal and rock can be categorized in such work materials that have high heterogeneity and brittleness. They limit the ser- 


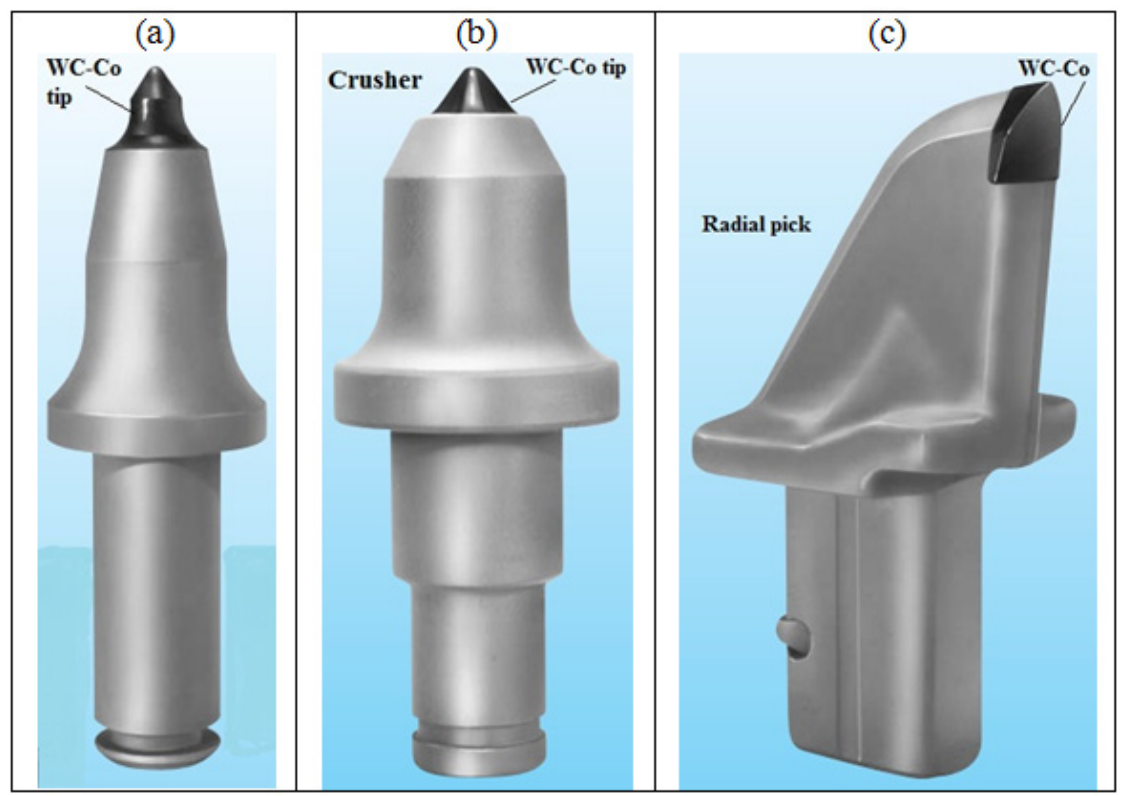

Fig. 1. Tools of different shapes (a) Conical Pick; (b) Crusher; (c) Radial pick [38]

vice life of the excavating tools largely. Coal is an important source of energy all over the world. There is a huge demand of coal in power and steel industries. High production rate is greatly affected by the performance of mining machineries (e.g. continuous miner, roadheader, shearer, etc.) and a selection of excavating tools. The mining based tools are equipped with WC-Co cemented carbide in different shapes and sizes. In coalmines, mainly cutters or picks, such as conical picks, radial picks, crushers and headers are used for excavation. The different shaped tools and a roadheader are shown in Fig. 1 and Fig. 2, respectively. The variation in geological conditions of the underground mines becomes damage prone for WC-Co. According to Altinoluk (1981), worn and damaged tools require much higher force than that of new sharp tools. It is always desirable for the tools to have a longer life span [1]. For any machining processes, the operating parameters play a vital role to get the accurate results. Also, a proper diagnosis is necessary to avoid unpredictable breakdown [18, 23, 24].

In the present work, various tribological behaviour in the WC-Co part of the radial picks have been analysed by using high resolution microscope (FESEM). Both the picks were equipped in a roadheader for coal excavation.

\section{LITERATURE SURVEY}

Radial and conical picks are generally employed in the underground mining machineries, such as continuous miner, road headers, and shearers. They have various advantages at different working conditions. In the case of conical picks it has been found that as the depth of cut increases the need of specific energy for cutting reduces [9]. Due to rotation in the bit holder, the conical picks are found to have uniform wear and symmetry in the shape during cutting which prolongs its service life $[21,25,45]$. In addition, it has also been noticed that longer service life and higher efficiency of the conical pick is only due to the rotation in the bit holder. In case of improper operational conditions, it is not necessary that the conical picks will provide higher efficiency than radial picks [20]. The Bureau of Mines carried out some tests in which the radial and conical picks were compared on the basis of cutting force required to make a cut of similar nature in in-situ coal mass. It was found that radial picks require less cutting force than conical picks [41]. Another laboratory test was conducted by the Bureau of Mines in which the radial pick and the conical pick were used to cut four different types of rock (uniaxial compressive strength ranging from $50 \mathrm{MPa}$ to 200 $\mathrm{MPa})$. The test results showed that radial pick had lower cutting force, greater fragmentation efficiency, and less distortion than conical picks $[12,41]$. Radial picks are superior to conical picks when they are maintained in a good condition. However, wearing occurs rapidly in the radial picks when used to cut high strength and abrasive rocks [11, 22, 35]. 


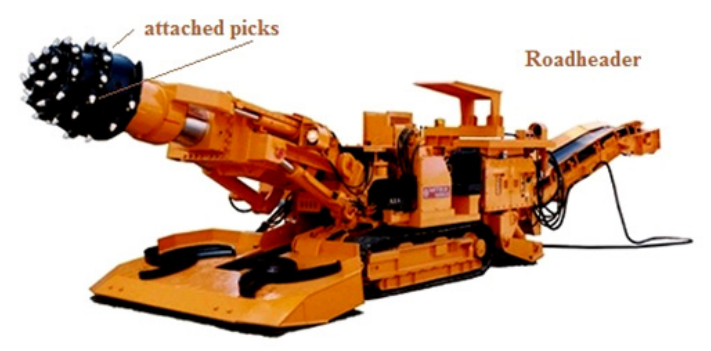

Fig. 2. A road header with attached picks [37]

Many researchers have defined the term "wear" in various ways. Zum Gahr (1987) stated that wear is an undesirable loss of the constituent material from a solid surface under the influence of mechanical interactions, such as contact and relative motion between two bodies. This loss of materials is continuous in nature [46]. According to Maidl et al. (2008), evaluation of the economy of process and the efficiency of operation depend upon wear phenomena of the cutting tool. Tool wearing happens due to relative frictional motion between coal/rock and tool. It is highly undesirable from the tool life point of view [31]. In addition, Stolarski (2000) has explained that wearing properties of a material are behavioural parameters and are influenced by the operational conditions [40].

As the WC-Co is a main part of the mining tools, wear assessment has been mainly focused in it. Cemented carbide (CC) is a very hard and brittle material. According to Aylward and Friendly (1994), the density of CC is 13-15 $\mathrm{g} / \mathrm{cm}^{3}$. The individual densities of $\mathrm{WC}$ and Co are $15.7 \mathrm{~g} / \mathrm{cm}^{3}$ and $8.9 \mathrm{~g} / \mathrm{cm}^{3}$, respectively [2]. For manufacturing $\mathrm{CC}, \mathrm{WC}$ and $\mathrm{Co}$ are mixed homogeneously under the high pressure of 100$420 \mathrm{MN} / \mathrm{m}^{2}$ in presence of high heat and vacuum. This process is called cementation of WC grains into Co content. The mixture is sintered at the temperature of $1435^{\circ} \mathrm{C}[8,36]$. The performance of the $\mathrm{CC}$ depends on different parameters, such as, WC grain size, amount of binder (cobalt) content, carbon content, and presence of porosity [8]. Milman et al. (1999) have concluded that presence of fine WC grain makes the $\mathrm{CC}$ very hard and wear resistant [33]. It has been reported that an increase in the cobalt content reduces hardness [10] and increases transverse rupture strength [8] of the CC. However, after certain limit $(20 \%)$, increase in the amount of cobalt binder can separate the carbide grains [8]. Carbon content negatively affects the mechani- cal properties of CC. Grain growth of WC is also affected by carbon content [30]. Porosity is a defect which can reduce the transverse rupture strength of the CC [44].

Literature, describing the wear mechanisms in radial picks, is few in number. However, other tools, such as drill bits and conical picks have been evaluated for their wear mechanisms after using them in different working environments. Drill bits are used for drilling hard rock structure whereas picks or cutters are used to cut soft rocks and coal in mines. As stated by Beste (2004), brittle fracturing of rocks and coals is performed by three methods. They are rotary percussive (for very hard and abrasive rocks), rotary crushing (for rather soft rocks), and cutting (for soft and non-abrasive rocks and coals). The tools used for above three methods are drill bits, tri-cone bits, and cutting picks, respectively [3].

In the case of rock drilling many factors such as rock type, abrasiveness, temperature generated during drilling, rock penetration and corrosive environment around the tool are responsible for various wear mechanisms. Under dry condition, the WC-Co can be damaged in three ways, i.e., cobalt removal, cracking of grain boundary, and WC grain fragmentation, which occur intermittently $[4,5]$. The rock drill has a number of button shaped $\mathrm{CC}$ which perform drilling process in a complex condition. Different rock properties, mineral content, and various machining parameters create complexity for the tools $[6$, 39]. Different drilling methods have their own wearing effect in the tools. In case of percussive drilling, the wear pattern is caused by mainly fatigue whereas cracks and abrasion are the failure modes in case of rotary drilling [28, 42]. LarsenBasse $(1973,1985)$ has stated that Microspalling, Abrasion wear, WC grain pull out, Extrusion of binder metal and Reptile skin are common wear mechanism in the WC-Co [28, 29]. Beste et al. (2008) have concluded that corrosive degradation and oxidation are responsible for erosion of binder content in drill bits. In addition, rock penetration also enhances the wear phenomena in drill bits significantly [7]. Many researchers have reported that heat generation during rock drilling adversely affects the service life of the tools. According to Fish et al. (1959), softening of the tool material occurs under the influence of high frictional heat [19]. Kindermann et al. (1999) have reported fatigue effects produced by variations in temperature (range $25^{\circ}-900^{\circ} \mathrm{C}$ ). 
At higher temperature, cobalt binder undergoes oxidation phenomenon [26]. Lagerquist (1975) has found thermal fatigue crack propagation in cemented carbide [27]. On the basis of research work, Mary and Gonseth (1993), have divided the mechanical behaviour of the WC-Co into three temperature range. It is brittle below $500^{\circ} \mathrm{C}$, tough in a range of $500-800^{\circ} \mathrm{C}$, and plastically deformed above $800^{\circ} \mathrm{C}$ [32].

In case of coal cutting, mainly conical picks have been previously investigated for wear mechanisms. Dewangan et al. $(2015,2015)$ and Dewangan and Chattopadhyaya (2016) have done characterization of wear mechanisms in $\mathrm{CC}$ tip and steel body of the conical picks, which got damaged after in situ coal mining operation. In the steel body, coal intermixing, rock channel formation, rock cover formation, plastic deformation, crushing, and material overlapping have been observed. In the $\mathrm{CC}$ tip, the mechanisms such as cracking and crushing, coal/rock intermixing, chemical degradation along with abrasion, long and deep cracks have been reported as main wear mechanisms $[13,15,16]$. In another work, Dewangan and Chattopadhyaya (2015) have investigated two new types of failure mechanisms. They are cracks with overlapping surfaces and grinding effect. Also, the reason behind the roughness of WC grains has been found to be formation of $\mathrm{WO}_{3}$ on the corroded surface of carbide [14]. According to Wang et al. (2015), Abrasion and tipping have been observed as main failure behaviour in WC-3.5\% Co cutter head used for mining application [43].

\section{EXPERIMENTAL}

Two radial picks have been collected from an underground mine. The picks were used for coal excavation. The grade of coal was W-II. A roadheader (Alpine Miner-AM 50) was used as an excavating machine. The power of the cutter motor and speed of the cutter head were $100 \mathrm{~kW}$ and 60 $\mathrm{rpm}$, respectively. Both the picks were used for a period of 10 hours. The mine, under study, is the same as that previously considered by Dewangan et al. (2015) [15] for investigating wear mechanisms in a conical pick.

Worn out radial picks are shown in Figure 3(a) and 3(b). Appropriate sized samples, i.e., sample ' 1 ' and sample ' 2 ', have been prepared by cutting the $\mathrm{CC}$ part from the tool body. For cutting
Table 1. Specification of FESEM

\begin{tabular}{|c|l|c|}
\hline No. & Specification & Parameters \\
\hline 1 & Resolution & $0.8 \mathrm{~nm}$ at 15 KV, 1.6nm at 1 KV \\
\hline 2 & Magnification & $100 \mathrm{~V}$ TO $30 \mathrm{KV}$ \\
\hline 3 & $\begin{array}{l}\text { Acceleration } \\
\text { voltage }\end{array}$ & $12 \mathrm{pA}$ to $100 \mathrm{nA}$ \\
\hline 4 & Gun type & Schottky Field Emission Electron Gun \\
\hline 5 & $\begin{array}{l}\text { Maximum } \\
\text { probe current }\end{array}$ & $\begin{array}{r}\text { SE, In-Lens, BSE, Retractable STEM } \\
\text { with Bright and dark field }\end{array}$ \\
\hline 6 & Detectors \\
\hline
\end{tabular}
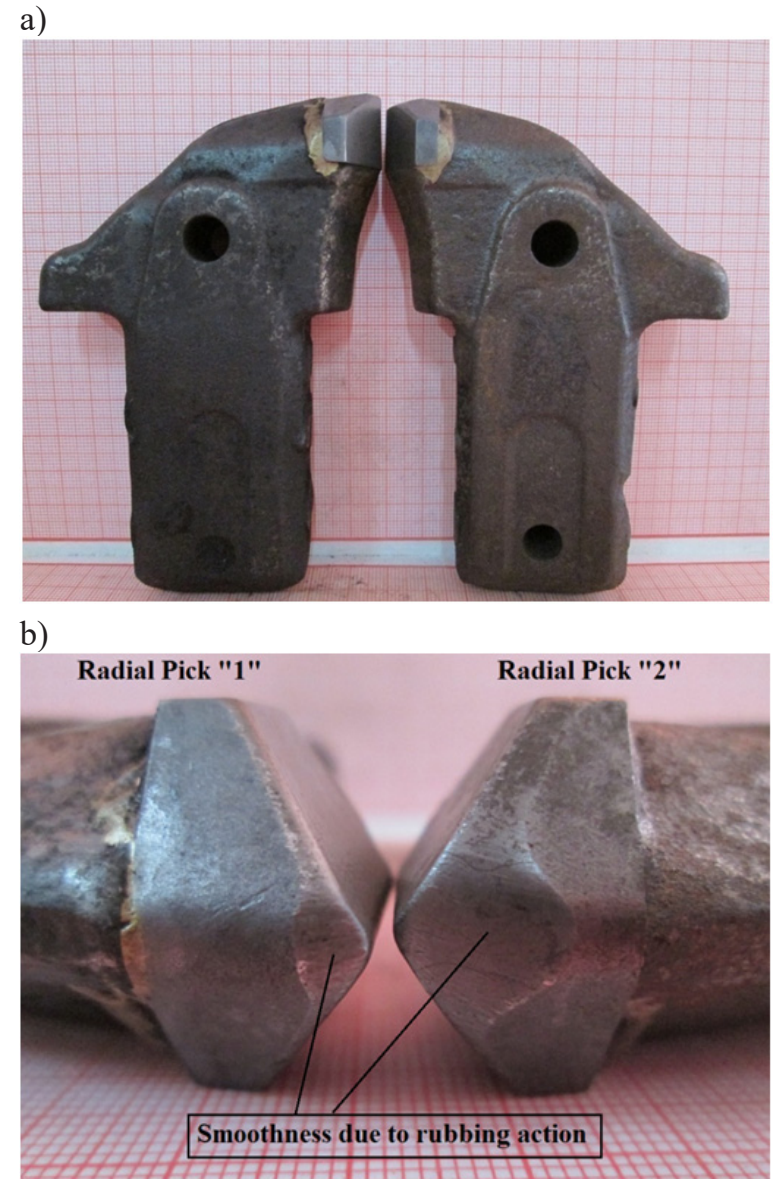

c)

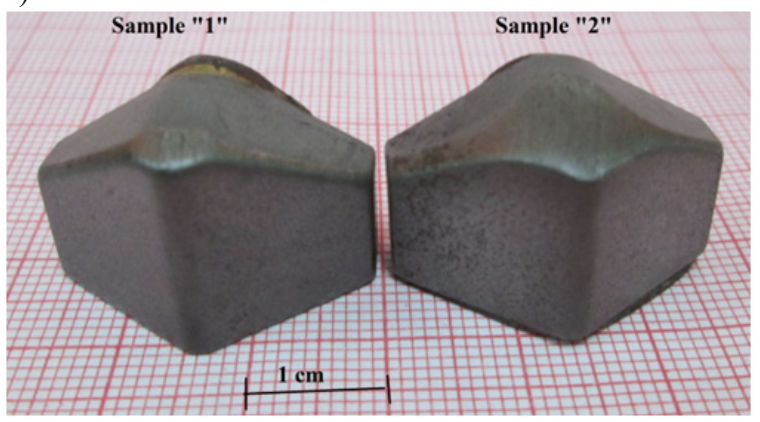

Fig. 3. a) Radial picks used for experimental work; b) close view of CC surfaces of both the picks; c) two samples have been prepared by cutting them properly by EDM 
purpose, Electro Discharge Machining (EDM) has been used so that the cut surface of samples can be smooth. It is necessary for proper adjustment of the samples on the work-piece stand of FESEM instrument. Samples are shown in Figure 3(c). By observing both the tools by naked eye, smoothness on the CC surface due to rubbing action of coals can be found. Pick " 2 " has undergone high frictional resistance and therefore it is comparatively more damaged than Pick " 1 ". It can be observed in Fig. 2(b) that area of smoothness in sample ' 2 ' is greater than sample ' 1 '.

For critical analysis of wear mechanisms, FESEM Supra 55 (Carl Zeiss, Germany) has been used. The specification of the instrument is given in Table 1.

\section{Investigation and analysis}

On the basis of present observations and considering previous literature, wear mechanisms in the radial picks have been divided into five categories:

1. Abrasion on individual grain

2. Corrosion in carbide grains

3. Fragmentation and removal of WC grains

4. Pores in WC grains

5. Coal and rock embedding

(1) Abrasion on individual grain: This phenomenon was found on the surface of single WC grain in a group of crushed grains. The possible cause of this phenomenon is similar to that of cracking and crushing. Due to sudden impact imposed by coal mass, tools get cracked and crushed. In the present study, abrasive rock particles have affected the particular individual grains comparatively in lesser amounts. When an area of WC grain gets affected by abrasive rock materials under the influence of heavy shocks, many grains become crushed and cracked as a result. Among all affected grains, there is a little number of grains which do not get severely crushed but the sign of severe abrasion on the grain can be found easily. An abrasive effect can be seen in individual grains which is available in between a number of crushed grains (Fig. 4). An enlarged view of selected grain has been shown in Fig. 5. Sometimes more abrasive action breaks the grain. A clear view of abrasion with cracking has been shown in Figure 6.

(2) Corrosion in carbide grains: Corrosion phenomenon in the cemented carbide can be manifested by the virtue of roughness present

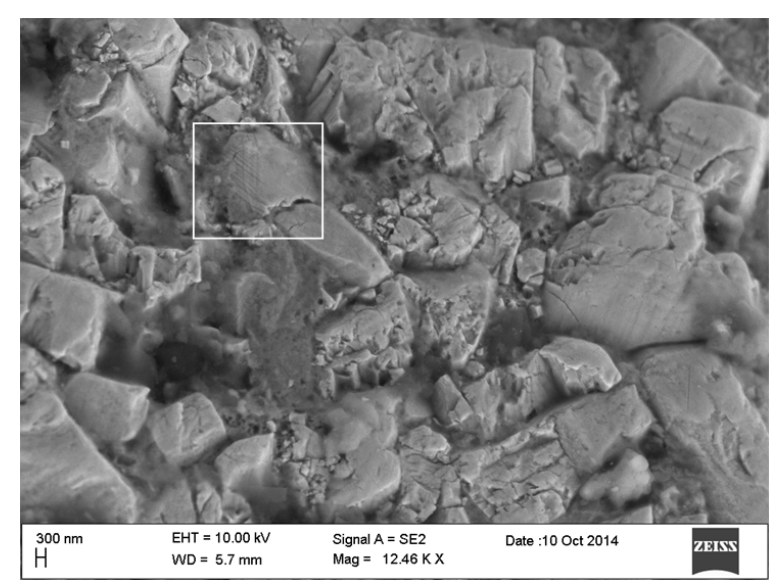

Fig. 4. Abrasion on individual grain (selected white rectangular part)

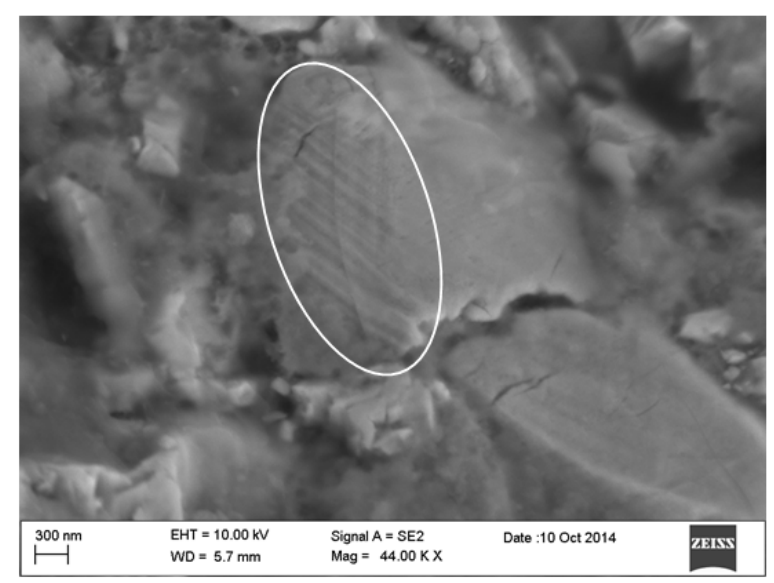

Fig. 5. Enlarge view of selected white rectangular part from fig. 4 [Magnification $=44 \mathrm{~K} \times$ ]

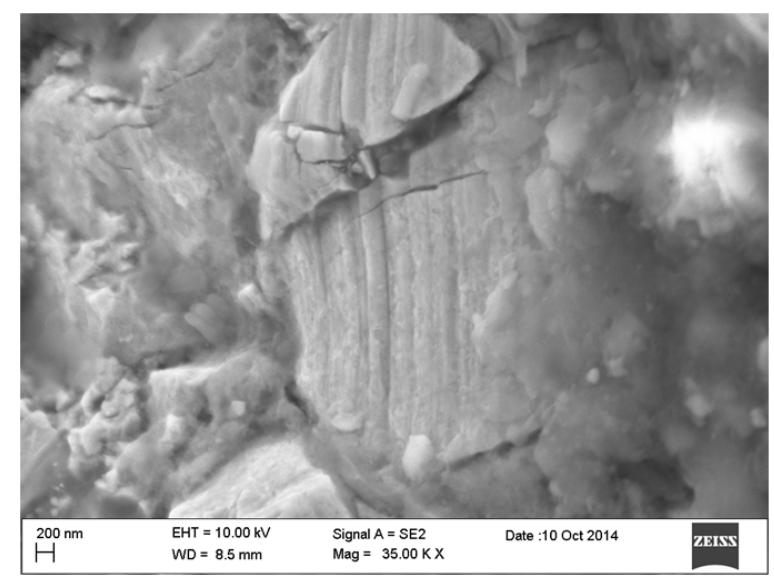

Fig. 6. Crack in an individual abraded WC grain

on the carbide (WC grain) surface. After critical analysis of wear mechanisms in cemented carbide, roughness in the WC grains has been reported by Dewangan and Chattopadhyaya (2015) [14]. On the basis of laboratory test results, Ech- 


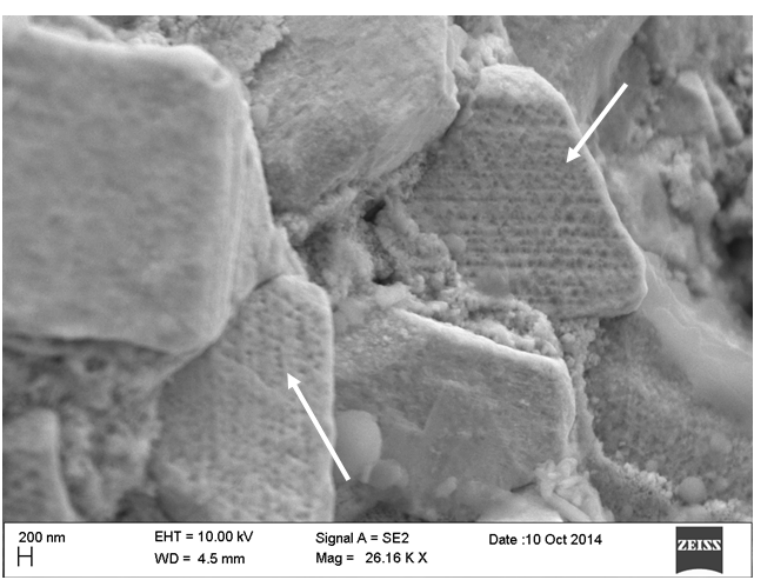

Fig. 7. Corrosion in carbide grains (white arrows show corroded grains)

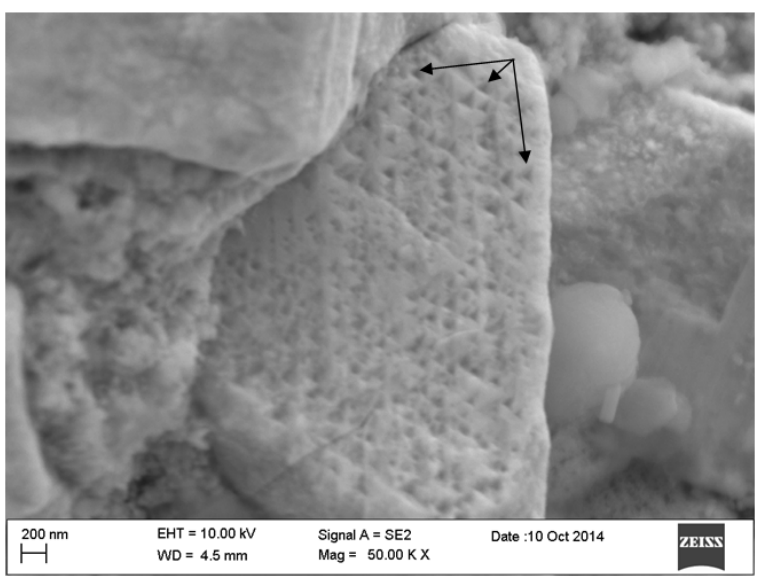

Fig. 8. A clear view of triangular notches in $\mathrm{WC}$ grains (black arrows)

tenkamp (1978), has observed roughness in the carbide grains in the form of pores and notches [17]. Similar phenomena (roughness and triangular notches) have been observed in the CC part of the radial picks also. The most probable reason behind this mechanism is the presence of chemically activated mine water inside the underground mine. High heat generation due to heavy impacts and shock hastens this process. Figure 7 shows clear image of rough surfaces of WC grains due to corrosion. Also, a more magnified part of Figure 7 is shown in Figure. In this, triangular notches are present in excess amount. It can be reported that corroded WC grains have less wear resistant property and hence easy breakage could be observed under the influence of heavy shocks.

(3) Fragmentation and removal of WC grains: The cutter head of road header was rotated at a speed of $60 \mathrm{rpm}$. The power of the cutter motor was $100 \mathrm{~kW}$. With this high speed, continuous rotation of the cutter head causes the tools to get sudden shocks and heavy impacts from the coal mass. It results in WC grain cracking. Further impacts on the cracked WC grains facilitate the crushing phenomenon of the grains. A condition is reached when an individual grain gets fragmented because of crushing. The fragmented particles continuously dislodge resulting in overall grain removal. Figure 9 shows the fully cracked and crushed cemented carbide part.

(4) Pores in WC grains: In high magnification values, pores can be observed in some WC grains. These pores are available in a series in the $\mathrm{WC}$ grains. The reason behind the porous surface of the WC grains is mainly corrosive degradation of the CC. Due to availability of these pores, the WC grains become crack prone. On the applica-

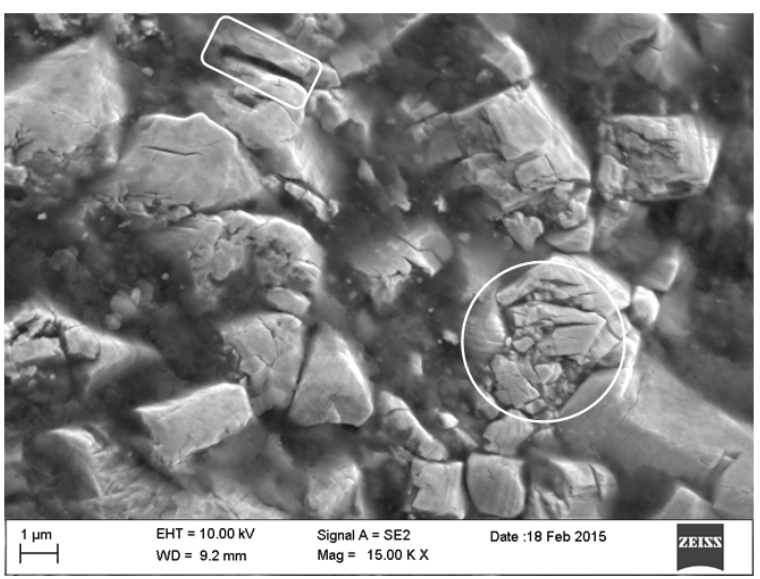

Fig. 9. Grain fragmentation and grain removal; white circled part shows the fragmented grains in an individual WC grain; rectangular part shows the empty place due to removed fragmented particles from crushed WC grain

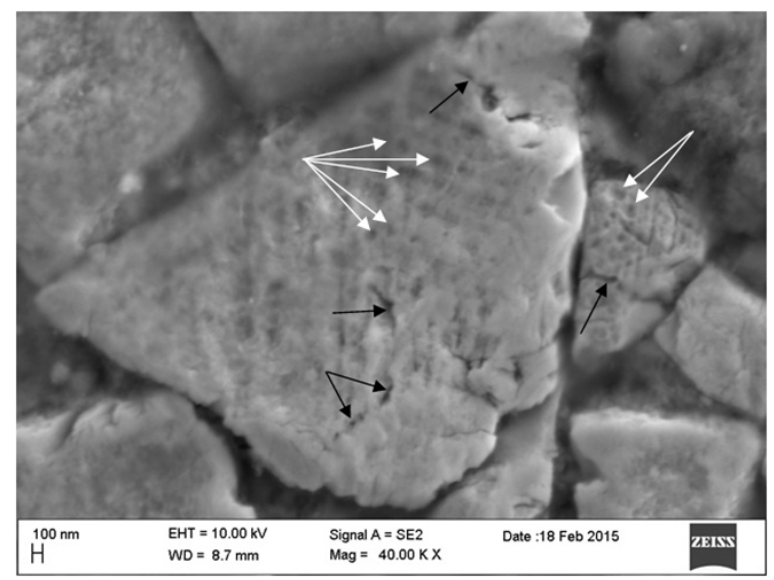

Fig. 10. Pores (indicated by white arrows) and cracks (indicated by black arrows) in the WC grains 


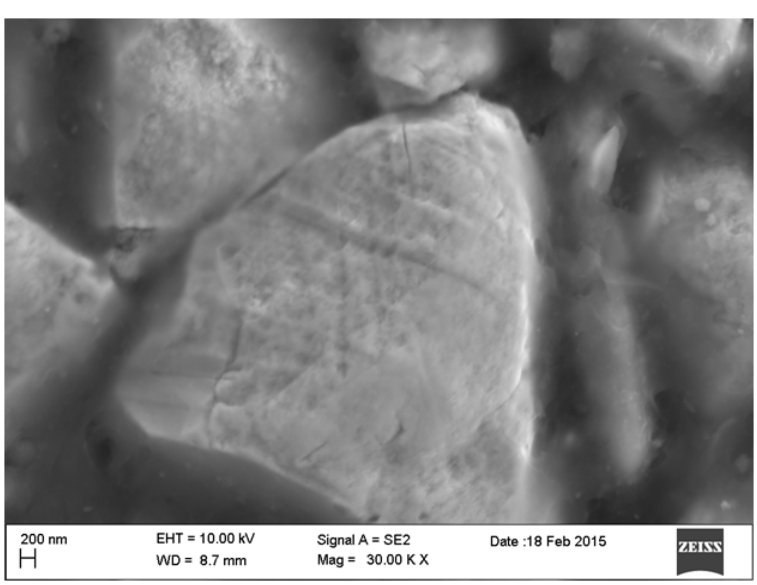

Fig. 11. Another image of WC grains with shallow pores on the surface

tion of high impacts, the grains may crush into a number of parts. In Figure 10, one can easily observe the pores and cracks in the WC grains. Pores are shown by white arrows and cracks are shown by black arrows (Fig. 10). Figure 11 shows another image of WC grains with a number of shallow pores on the grain surface.

(5) Coal and rock embedding: It is a common wear phenomenon which can be observed in any type of coal cutting tool. The tools continuously come into contact with heterogeneous coal and rocks. Sometimes a lump of coal adhered with the surface of the tool tip. Due to continuous impact during the coal cutting process, a condition reached when some coal particles entrench inside the microstructure of CC. As the cobalt content is comparatively soft and ductile in nature, it allows brittle and sharp particles of coal (included with some rocks) to entrench and embed inside easily. This phenomenon is highly unfavourable because it degrades the binder content. The degradation happens when coal and rock particles become intermixed with binder content. In this case, the binder part is no longer able to bind the WC grains properly. The loosely bonded WC grains easily remove out from the CC microstructure. The phenomenon of coal and rock embedding is shown in Figure 12.

The embedding of coal and rock particles into the microstructure of WC-Co has been established by EDS images \{Fig. 13 (a, b, c) \}. The embedded dark parts in the FESEM images have been selected thereby the intermixed elements can be observed on energy dispersive spectrographs. For the purpose, three different parts of the intermixed zones have been analysed on the same microscopic image.
As shown in Figure 13 (a), an area spectrum 1 has been selected on a dark part of the microstructure of WC-Co. The corresponding spectrograph shows a presence of various external elements (other than $\mathrm{W}$ and $\mathrm{Co}$ ) in weight percentage. These elements are $C=66.12 \%$; $O=11.18 \% ; A l=1.71 \% ; S i=4.74 \% ; C a=2.03 \%$. It can be observed that mainly carbon and oxygen are available in excess amount. Other elements, such as, $A l, S i$, and $C a$ are comparatively fewer. Here, a large quantity of carbon shows that coal entrenchment in this area is significant whereas $\mathrm{Al}, \mathrm{Si}, \mathrm{Ca}$ and $\mathrm{O}$ are representing the availability of rock particles.

In Figure 13 (b), another rectangular area spectrum 2 is selected on a different dark (intermixed) part. Similar to previous cases, various external elements have been reported. They are: $C=17.85 \% ; O=26.92 \% ; N a=0.58 \% ; A l=2.50 \%$; $\mathrm{Si}=6.56 \% ; \mathrm{Ca}=0.29 \% ; \mathrm{Fe}=5.64 \% ; \mathrm{Ni}=2.50 \%$. Except $C$, other elements are common constituents of the earth rock.

In case of Figure 13 (c), a point spectrum 3 is selected on the bright WC grain. The corresponding EDS is showing only three elements, such as, $W(90.17 \%), C(8.62 \%)$, and $O(1.22 \%)$. Higher amount of $\mathrm{W}$ is obvious because the point is on WC. In this case, the amount of C is comparatively lower than that of both the previous cases. There are two reasons for the presence of the amount of carbon: (1) The microstructure of the CC is already degraded, therefore some amount of coal (or carbon) are shown by spectrograph. (2) Being a main constituent of the tungsten carbide (WC), the peak of carbon can be found in the EDS.

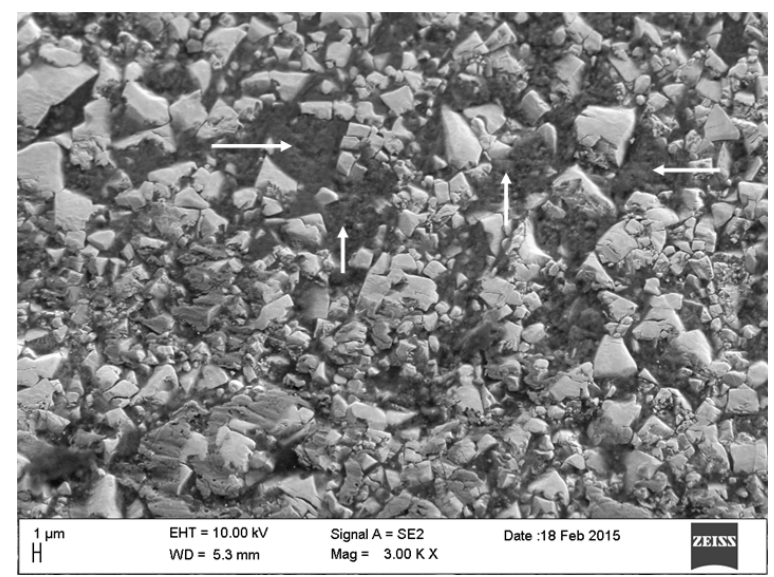

Fig. 12. Coal entrenchment into the microstructure of CC (white arrows are indicating the dark zone of coal and rock materials) 
a)

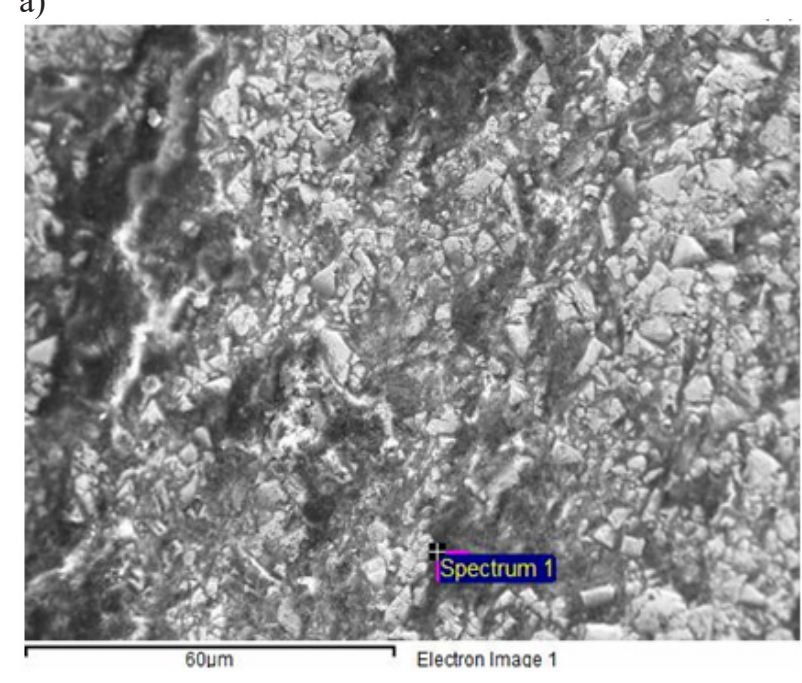

b)

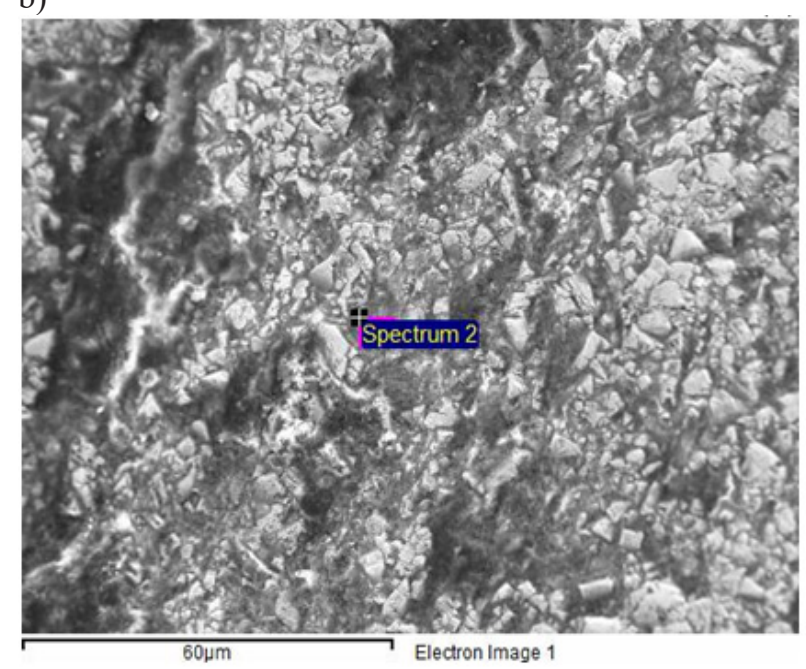

c)

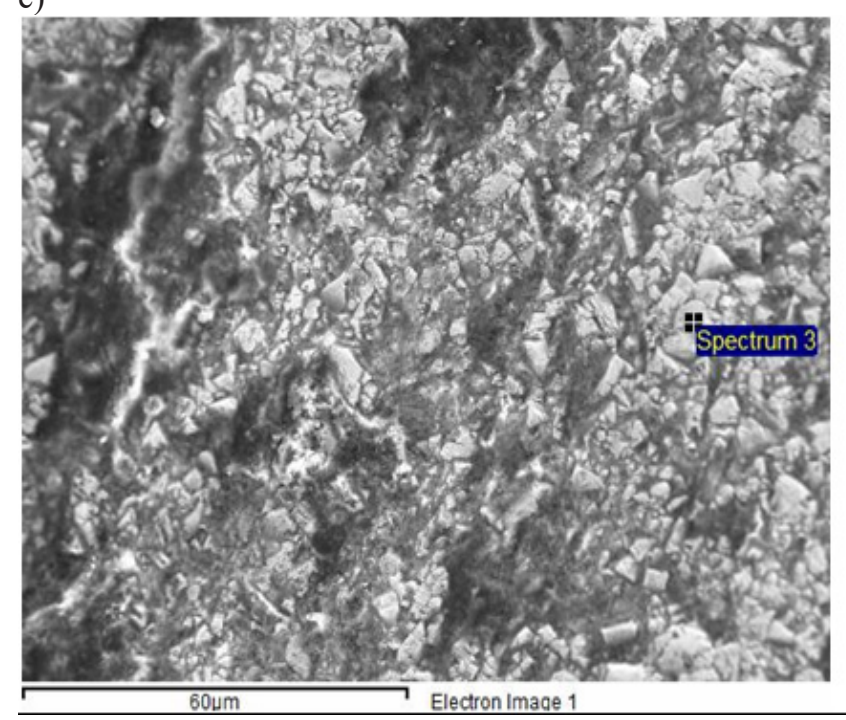

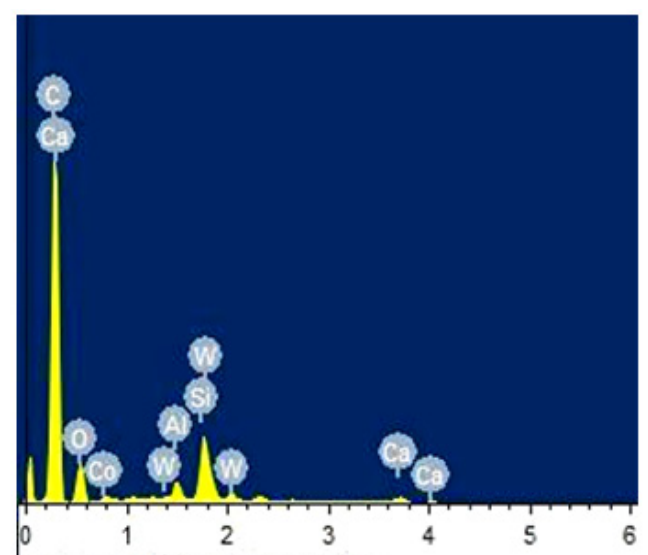

Full Scale $44726 \mathrm{cts}$ Cursor: 0.000

$\mathrm{C}=66.12 \% ; \mathrm{O}=11.18 \% ; \mathrm{Al}=1.71 \% ; \mathrm{Si}=4.74 \%$; $\mathrm{Ca}=2.03 \% ; \mathrm{Co}=1.73 \% ; \mathrm{W}=12.49 \%$

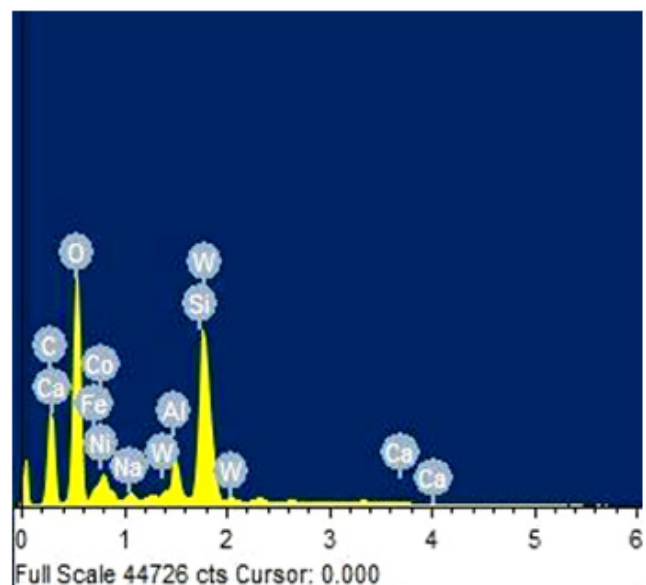

$\mathrm{C}=17.85 \% ; \quad \mathrm{O}=26.92 \% ; \quad \mathrm{Na}=0.58 \% ; \quad \mathrm{Al}=$ $2.50 \% ; \quad \mathrm{Si}=6.56 \% ; \quad \mathrm{Ca}=0.29 \% ; \quad \mathrm{Fe}=5.64 \%$; $\mathrm{Co}=9.43 \% ; \mathrm{Ni}=2.50 \% ; \mathrm{W}=27.73 \%$

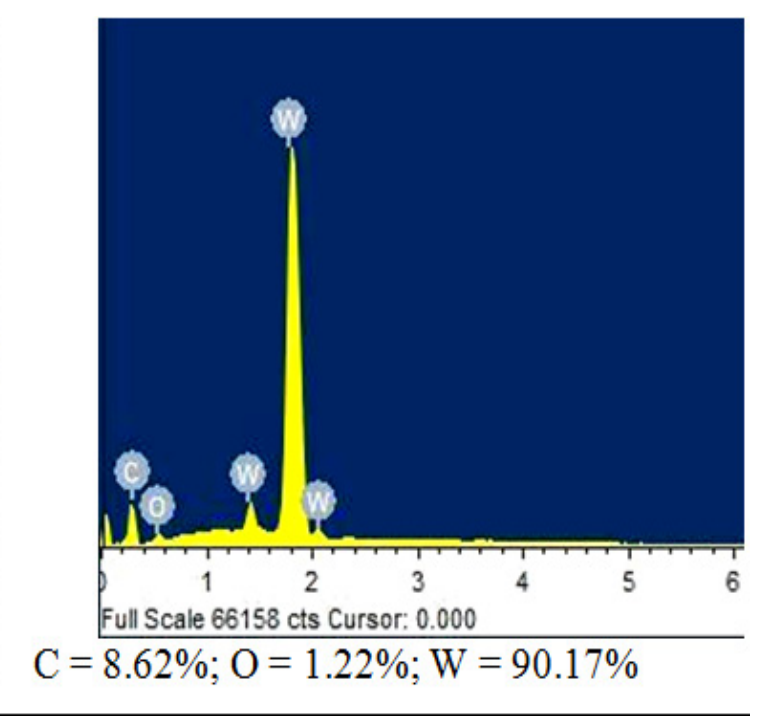

Fig. 13. EDS images: a) An area spectrum 1 selected on dark intermixed zone and its spectrograph; b) Another area spectrum 2 selected on different part of dark intermixed zone and its corresponding spectrograph; c) A point spectrum 3 on the WC grain and its spectrograph 
In addition to analysis of microstructure of the WC-Co, coal sample of the considered underground mine has also been observed by EDS for its elemental composition. Figure 14 \{a) and (b)\} shows the microscopic images of coal sample and the spectrographs of selected area on the images. By examining both the spectrographs, it can be noted that $C, O, A l, S i, C a$, and $S$ are mainly present as main constituents of coal sample. $C$ represents coal particles and rest of the elements are indication of rock constituents. Two other elements, i.e., $\mathrm{K}(0.35 \%)$ and $\mathrm{Ti}(0.59 \%)$ are also present in traces.

The elements of coal sample have been noticed as intermixed external materials in the microstructure of the WC-Co. In this way, the results of Figure 14 corroborate the results of Figure 13.

\section{DISCUSSION}

The fundamental aim behind tribological assessment of any tool is to investigate the cause of wear and, accordingly, to modify the concentration of the tool material for avoiding such failures. To study the wear mechanisms in WC-Co cemented carbide has been an interesting subject for a long time. The ongoing research is necessary in order to improve the useful properties (mainly wear resisting property) of the cemented carbide. As the size of the WC grains greatly affects the performance of the $\mathrm{CC}$, the research has been focussed on the development of nano-sized WC grains in the last few years. The significant improvements in the hardness, strength and tribological properties have been reported in the nanostructured cemented carbide. The functionally
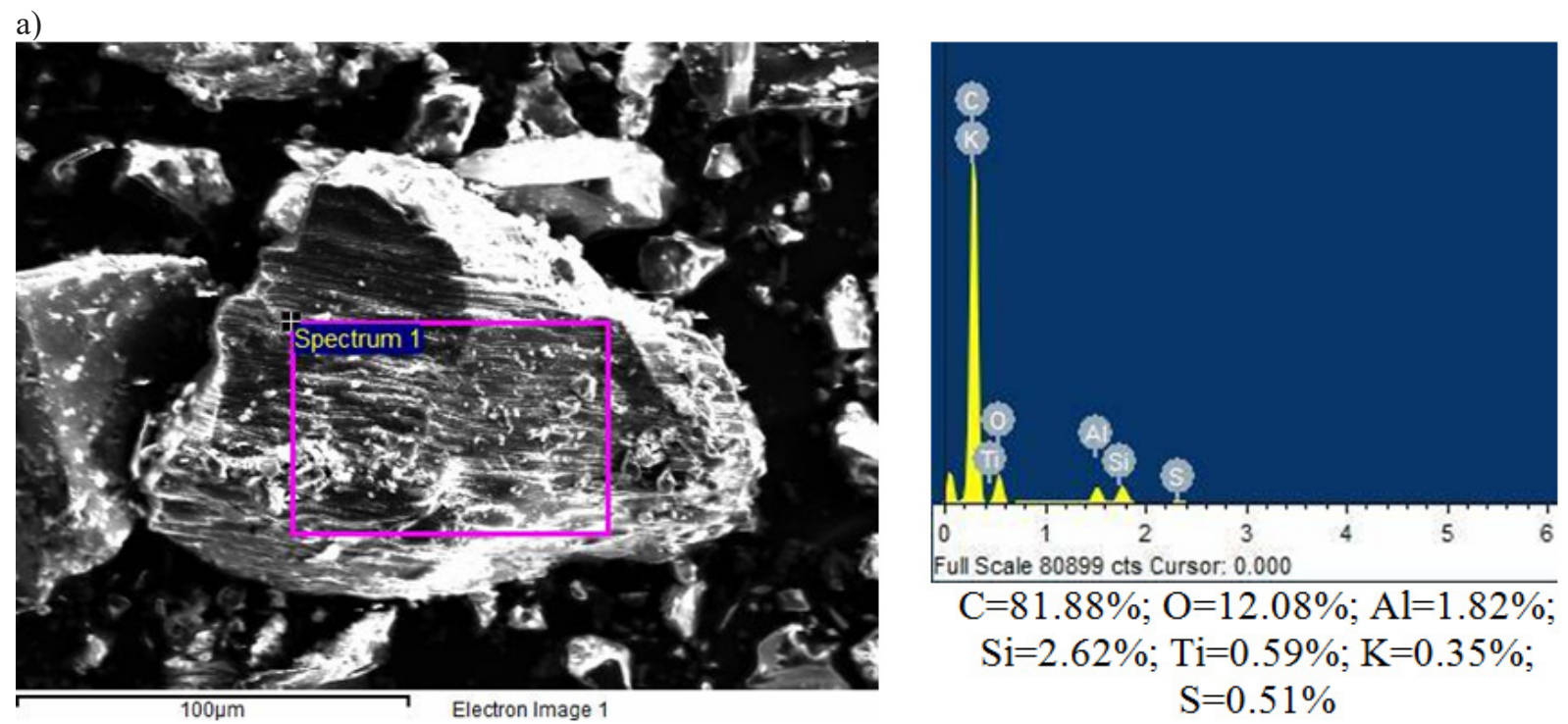

b)
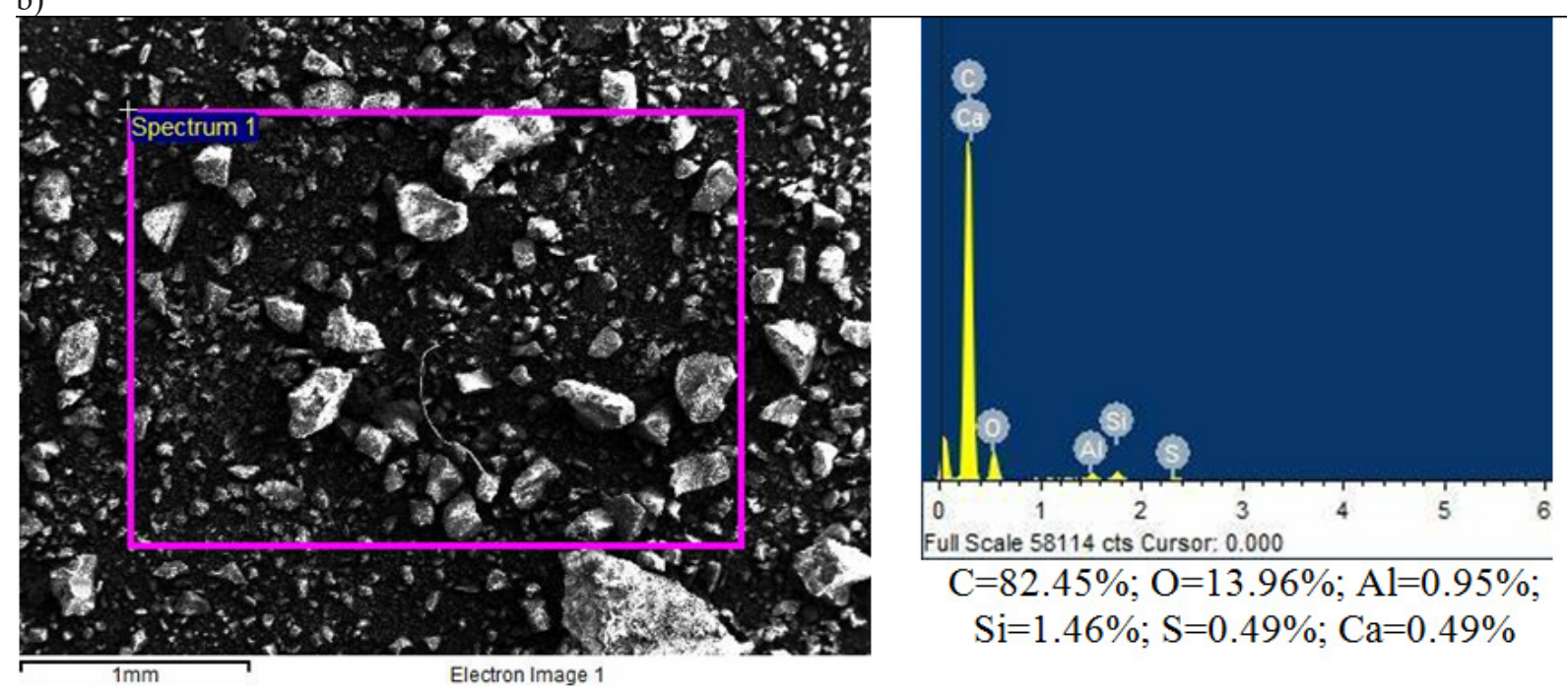

Fig. 14. EDS of coal sample of underground mine 
graded CC and binder-less CC are also recent developments in the cemented carbide which have improved mechanical properties especially high wear resisting properties [34].

\section{CONCLUSION}

In the present work, an attempt has been made to understand the characteristics of various tribological phenomena in WC-Co part of the two radial picks which were used for coal mining by using a roadheader. For the purpose, FESEM has been used to capture highly magnified images of worn out parts of the WC-Co. On the basis of observation five types of wear mechanisms have been reported. They are Abrasion on individual grain; Corrosion in carbide grains; Fragmentation and removal of WC grains; Pores in WC grains; and Coal and rock embedding. High heterogeneity of coal, presence of abrasive rock particles, and varying geological conditions in underground mines vouch the possibilities of tool damage.

Abrasion on individual grain is a distinguished wear phenomenon in which a WC grain (in a group of cracked and crushed grains) becomes locally abraded. It has a definite sign of abrasion. Sometimes, these locally abraded grains may crack due to excess impacts. The reasons behind fragmentation and removal of WC grains are sudden impacts on the tool caused by brittle coal mass. Continuous hitting results in the formation of fragments of the WC grains. In the case of WC, Corrosion and Pores are complementary to each other. The chemically activated underground mine water, heat fluctuation of the tool tip, and other geological conditions enhance the corrosion phenomenon and thereby generation of pores on the surface of carbides. The process of coal and rock embedding occurs during excavation when the minor cracks provide an easy path to coal and rock particles to get entrenched inside the microstructure of the WC-Co. The phenomenon of coal and rock embedding has been established by EDS. Mainly, C, O, Si, Na, Ca, Al, Fe, and $\mathrm{Ni}$ have been reported other as external elements. Among all the elements, $\mathrm{C}$ indicates the presence of coal particles whereas rest of the elements are the basic constituents of earth rock. The EDS results of coal sample corroborate with that of coal/ rock embedded zone in the WC-Co.

On the basis of present investigation and literature survey, a conclusion can be drawn that it is highly heterogeneous behaviour of coal and rock materials which does not confirm the domain of wear mechanisms in cemented carbide. In other words, the same samples may show other failure mechanisms if they are used in other coalmines.

\section{Acknowledgement}

The authors are thankful to the Central Research Facility provided by the Indian Institute of Technology (ISM), Dhanbad, India.

\section{REFERENCES}

1. Altinoluk S., Investigations into the Effects of Tungsten Carbide Composition and Geometry on the Durability of Rock Excavation Tools, Ph.D. Thesis, University of Newcastle upon Tyne, 1981.

2. Aylward G., Friendly T. SI Chemical Data. P. Storer, Ed, Wiley, Sydney, 1994.

3. Beste U. On the Nature of Cemented carbide Wear in Rock Drilling. Comprehensive summary of Uppasala dissertations from the faculty of Sc. and Tech., Acta Universitatis Upsaliensis, 2004.

4. Beste U., Hartzell T., Engqvist H., Axén N., Surface damage on cemented carbide rock-drill buttons. Wear, 249, 2001, 324-329.

5. Beste U., Jacobson S. Micro scale hardness distribution of rock types related to rock drill wear. Wear, 254, 2003, 1147-54.

6. Beste U., Jacobson S., Friction between a cemented carbide rock drill button and different rock types. Wear, 253, 2002, 1219-1221.

7. Beste U., Jacobson S., Hogmark S., Rock penetration into cemented carbide drill buttons during rock drilling. Wear, 264, 2008, 1142-51.

8. Bilgin N., Copur H., Balci C., Mechanical excavation in mining and civil industries. CRC Press, Boca Raton, 2013, 103-123.

9. Bilgin N., Demircin M.A., Copur H., Balci C., Tuncdemir H., Akcin N., Dominant rock properties affecting the performance of conical picks and the comparison of some experimental and theoretical results. Int J Rock Mech Min Sci, 43, 2006, 139-156.

10. Brookes K.J.A., Hardmetals and Other Hard Materials. International Carbide Data, 1992.

11. Cigla V., Ozdemir L., Computer modelling for improved production of mechanical excavators. In: Proc soc mining metall explor (SME) ann mtg, Salt Lake City, 2000, p. 12.

12. Demou S.G., Olson R.C., Wingquist C.F., Determination of bit forces encountered in hard rock cutting for application to continuous miner design. 
Report of investigations, US Bur Mines, RI 8748, 1983.

13. Dewangan S., Chattopadhyaya S., Characterization of wear mechanisms in distorted conical picks after coal cutting. Rock Mech Rock Eng, 49, 2016, 225-242.

14. Dewangan S., Chattopadhyaya S., Critical analysis of wear mechanisms in cemented carbide. Journal of Materials Engineering and Performance, 24, 2015, 2628-2636.

15. Dewangan S., Chattopadhyaya S., Hloch S., Critical damage analysis of WC-Co tip of conical pick due to coal excavation in mines. Advances in Materials Science and Engineering, 2015, 2015, 7 pages. http://dx.doi.org/10.1155/2015/292046

16. Dewangan S., Chattopadhyaya S., Hloch S., Wear assessment of conical pick used in coal cutting operation. Rock Mech Rock Eng, 48, 2015, 2129-2139.

17. Echtenkamp A.L., Combating Corrosion/Wear with the Hard Carbide Alloys. Proc. ASLE/Asme Lubrication Conf., Minneapolis, 1978.

18. Feldshtein E., Józwik J., Legutko S., The influence of the conditions of emulsion mist formation on the surface roughness of AISI 1045 steel after finish turning. Advances in Science and Technology Research Journal, 10, 2016, 144-149.

19. Fish B.G., Guppy G.A., Ruben J.T., Abrasive wear effects in rotary rock drilling. Trans. Mining Metall., 68, 1959, 357-383.

20. Fowell J., Hekimoglu O.Z., Altinoluk S., Drag tools employed on shearer drums and roadheaders. In: Proc 10th Turkish mining cong, Ankara, 1987, 529-550.

21. Hekimoglu O.Z., Investigations into performance of point-attack and radial type rock and coal-cutting picks. Trans Inst Min Metall, 107, 1998, 55-9.

22. Hurt K.G., Evans I., Point attack tools: an evaluation of function and use for rock cutting. Min Engr, March, 1981, 673-5.

23. Józwik J., Czwarnowski M., Angular positioning accuracy of rotary table and repeatability of fiveaxis machining centre DMU 65 monoblock. Advances in Science and Technology Research Journal, 9, 2015, 89-95.

24. Józwik J., Semotiuk L., Kuric I., Diagnostic of CNC lathe with QC 20 ballbar system. Advances in Science and Technology Research Journal, 9, 2015, 96-102.

25. Khair A.W., Research and Innovations for Continuous Miner's Cutting Head for Efficient Cutting process of rock/coal. Department of Mining Engineering, West Virginia University, Morgantown, USA. 17* International Mining Congress and Exhibition of Turkey- IMCET, 2001.
26. Kindermann P., Schlund P., Sockel H.G., Herr M., Heinrich W., Gorting K., Schleinkofer U., HighTemperature Fatigue of Cemented Carbides Under Cyclic Loads. Int. J. Refract. Metal Hard Mater., 17, 1999, 55-68.

27. Lagerquist M., A study of the thermal fatigue crack propagation in WC-Co cemented carbide. Powder Metallurgy, 18, 1975, 71-88.

28. Larsen-Basse J., Binder extrusion in sliding wear of WC-Co alloys. Wear, 105, 1985, 247-56.

29. Larsen-Basse J., Wear of hard-metals in rock drilling: a survey of the literature. Powder Metall., 16, $1973,1-32$.

30. Lee G.H., Kang S., Sintering of Nano-Sized WCCo Powder Produced by a Gas Reduction-Carburization Process. J. Alloy. Compd., 419, 2006, 281-289.

31. Maidl B., Schmid L., Ritz W., Herrenknecht M. Hard Rock Tunnel Boring Machines. Ernst \& Sohn, Berlin, 2008.

32. Mary D., Gonseth D.R., A new look at carbide tool life. Wear, 165, 1993, 9-17.

33. Milman Y.V., Luyckx S., Northrop I.T., Influence of Temperature, Grain Size and Cobalt Content on the Hardness of WC-Co Alloys. Int. J. Refract. Met. Hard Mater, 17, 1999, 39-44.

34. Mukhopadhyay A., Basu B., Recent developments on WC-based bulk composites. J. Mater Sci, 46, 2011, 571-589.

35. Plis N., Wingquist C.F., Roepke W., Preliminary evaluation of the relationship of bit wear to cutting distance, forces, and dust using selected commercial and experimental coal- and rock-cutting tools. Report of Investigations, US Bur Mines, RI 9193, 1988.

36. Rajput R.K., A Text Book of Manufacturing Technology: (Manufacturing Processes), Firewall Media, 2007, p 407.

37. Roadheaders. http://www.mitsuimiike.co.jp/english/product/excavator/rh/index.html

38. Sandvik Mineral and Ground Engineering Tools: (Product Catalogue). www.miningandconstruction.sandvik.com

39. Stjernberg K.G., Fisher U., Hugoson N.I., Wear mechanisms due to different rock drilling conditions. Powder Metall., 18, 1975, 89-106.

40. Stolarski T.A., Tribology in Machine Design. Butterworth-Heinemann, Oxford, 2000.

41. Sundae L.S., Myren T.A., In situ comparison of radial and point attack bits. Report of investigations, US Bur Mines, RI 9127, 1987.

42. Swick K.J., Stachowiak G.W., Batchelor A.W., Mechanism of wear of rotary-percussive drilling bits and the effect of rock type on wear. Tribol Int, 
25, 1992, 83-8.

43. Wang J., Wang H., Wang H. et al., Failure analysis of WC-3.5wt $\%$ Co cemented carbides in mining Applications. J. Wuhan Univ. Technol.- Mat. Sci. Edit., 30, 2015, 1279-85. DOI: 10.1007/s11595015-1308-1

44. Wood G.A., Quality Control in the Hard Metal In- dustry. Powder Metall., 13, 1970, 338-368.

45. Yilmaz N.G., Yurdakul M., Goktan R.M., Prediction of radial bit cutting force in high-strength rocks using multiple linear regression analysis. Int J Rock Mech Min Sci, 44, 2007, 962-970.

46. Zum Gahr K.H., Microstructure and wear of materials. Elsevier, Amsterdam, 1987. 